\title{
Research on the Improvement of Shared Massage Chair Based on User Journey Mapi
}

\author{
JI Qian ${ }^{1}$, ZHENG Jiayu ${ }^{1, a}$, ZHANG Yu ${ }^{1}$ \\ ${ }^{1}$ Huazhong University of Science and Technology,430074 Wuhan
}

\begin{abstract}
In this paper, the User journey map is an oriented graph to visualize the user's interaction with products and services. It helps designers to understand the user's feelings, thoughts, and behaviours at a specific time and look for the pain and opportunity points. The rapid development of shared massage chairs in recent years has been chosen as a typical case among a large number of shared products in this paper. According to the earlier survey, we noticed that users always had poor experience when use them. The user journey map has been used as a tool to analyze the experience of using a shared massage chair based on the observation and investigation of users in order to proposes new directions for its improvement.
\end{abstract}

\section{Introduction}

The shared massage chair allows everyone to enjoy a massage services at anytime anywhere by scanning the two-dimensional code. It is convenient to use for rest [1] when people are prone to experience physical and mental fatigue and most likely to have the need of rest, it helps users take advantages of their fragmented time to relax timely as well as provide users relatively accurate massage services. The Research Report on the 2017 Shared Massage Chair Market released by the Speed Research Institute pointed out that at present, China's massage apparatus market is in an ascending stage, and the health care population has increased by a large margin year by year [2].

User Journey Map is a design tool for carding user scenarios and experience problems [3]. It can disassemble fuzzy requirements into user behaviours, user feelings, usage scenarios and other elements visual expression, user behaviour indicates the pain and opportunities points [4]. It describes the user's experience through storytelling and presents information in a visual way [5].

Based on the user journey map of the interaction between users and shared massage chair, this paper summarizes the opportunity $(\mathrm{O})$ and pain $(\mathrm{P})$ points through the observation and interview, then focuses on the $\mathrm{O}$ and $\mathrm{P}$ points to find the breakthrough of the improvement, which will lead to the final design direction.

\section{Overview of the research process}

This paper conducts research preparation through literature review, analysis of existing products, conducting user surveys and collation of interviewee data through records and interviews. All interviewees data are aggregated into the user journey map and the $\mathrm{O}$ and $\mathrm{P}$ points are enumerated. Finally, the $\mathrm{P}$ and $\mathrm{O}$ points of shared massage chairs are analysed to propose design directions and plans. The main research methods and processes of this paper include those shown in Fig. 1

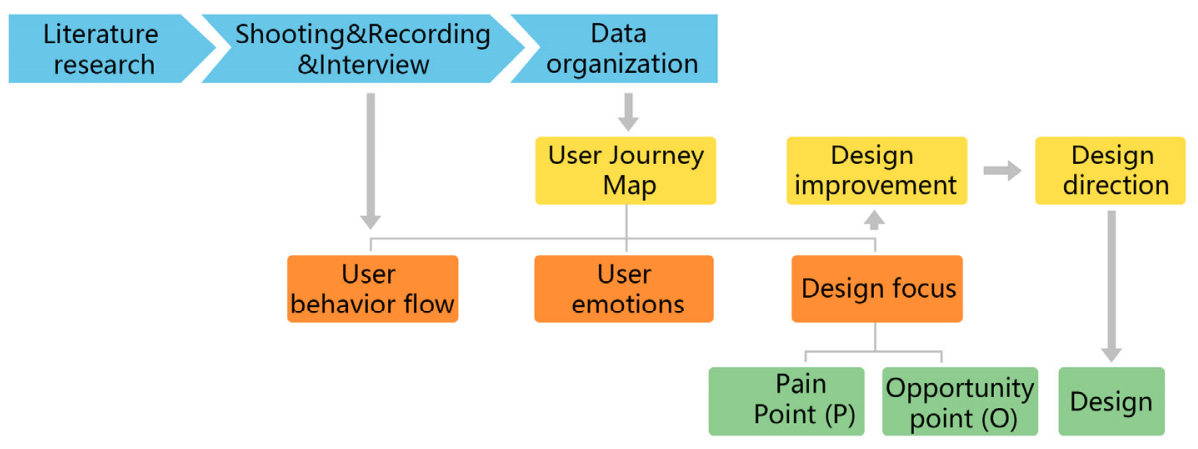

Figure 1. Main research methods and processes.

\footnotetext{
*Corresponding author: ${ }^{\text {a } 1104508815 @ q q . c o m}$
} 


\section{Preliminary investigation}

(1) Literature review

By analysing the current research status, related documents, the characteristics of shared massage chairs as well as the structure and appearance design of massage chairs. The purpose of literature research is to understand the research status, and to look for opportunities of existing research to find research space in this field.

As the "shared massage chair" is a relatively new product, academic search through various channels found, including CNKI, Google, etc., Wu Yan-jun elaborated on the design ideas of the payment board between the cloud server and the massage chair sharing the massage chair, introduced the realization methods of each function, and improved the stability and reliability[6].Some researchers have analysed the problem of shared massage chairs and system components based on the development status of shared massage chairs. This area of research is relatively new, although it will bring difficulties to the research, but it will also become a suggestion for a better development of the massage chair in the future.

(2) Existing product analysis

At present, the most popular brands of shared massage chairs are MOMODA and LEMOBAR. There are 6 features mainly as following: simple to use, cheap, providing massage services timely, occupying no private space, meeting the needs of health pursuit and leisure consumption, consumption upgrade in line with the needs of the times.

(3) User research

Through field investigation, 50 users were surveyed to analysed and organize more comprehensive and objective user experience data. In order to restore the authenticity of the observations, this research conducts field research at crowed places, where people flow is high and users are prone to fatigue, such as the airports, high-speed rail stations, cinemas, gymnasiums, beauty salons, shopping malls, supermarkets and stations. The main methods used in the main phases of the investigation include tracking shots, recordings and user interviews. The specific user survey process is shown in Fig. 2.

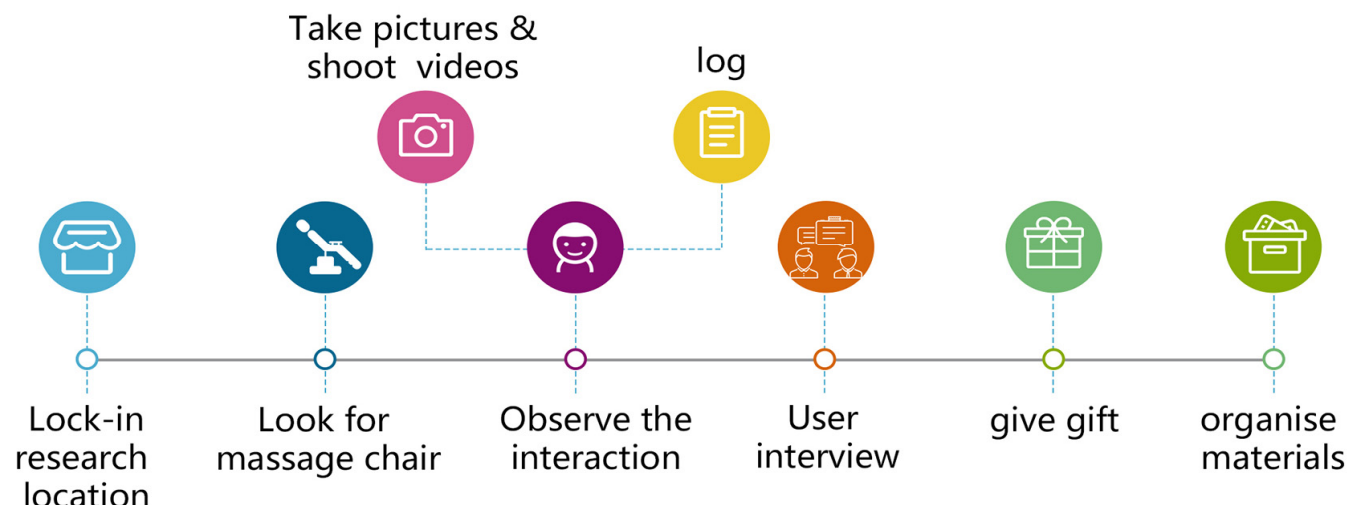

Figure 2. Specific user survey process.

The process of user research consists of two researchers. One is responsible for shooting, the other is responsible for observing and recording notes, and the researcher need not interrupt the users' normal behaviour when using products. After the filming is completed, the researcher will conduct about 15 minutes of interviews with the users. The main problems have been observed and the cause of the problems will be explored.

\section{User Journey Map}

The user journey map helps researchers to understand the needs and emotions of the target users through the entire interaction of the products, so as to achieve a better product and service. It can integrate the fragmentary observation and determine the $\mathrm{P}$ and $\mathrm{O}$ points for improvement. Different user journey maps are drawn for each typical user role or each type of user group, and the typical users' experience will be integrated to form a final user journey map. Compared to the user experience stage, the user behaviour is more micro-level, which is the flow of steps of specific user experience. As Fig.3 has shown, $\mathrm{P}$ and $\mathrm{O}$ points indicators to help identify opportunities for improvement. It is a design tool for combing user scenarios and experience problems. A requirement is presented horizontally according to user behaviour, and each behaviour node is rendered vertically. This process can disassemble the fuzzy requirements into user behaviours and user emotions, usage scenarios, etc. 


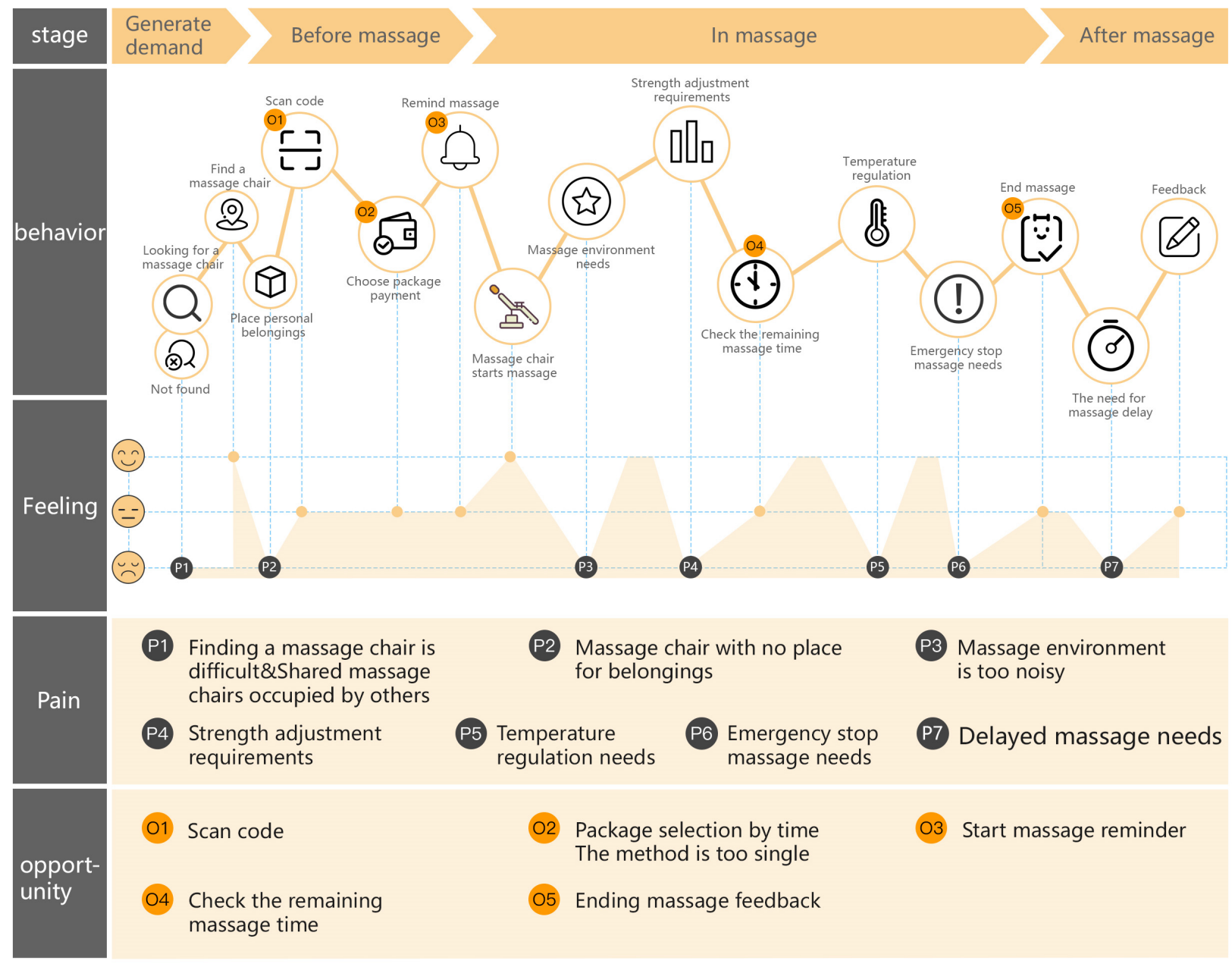

Figure 3. User journey map of shared massage chair.

\section{Problems and Improve design ideas}

Throughout the survey process of the shared massage chair, the output of each research process, the discovery of $\mathrm{O}$ and $\mathrm{P}$ and the transformation of the design of the research results have played a key role in the convergence. Tab.1 has shown improvement advice based on $\mathrm{O}$ and $\mathrm{P}$ points. Fig 4 has shown the improved design concepts.

Tab 1. Improvement points.

\begin{tabular}{|c|c|c|c|}
\hline point & Question of investigation & reason & Improvement direction \\
\hline P1 & Difficult to find a massage chair & $\begin{array}{l}\text { not evenly distributed, no navigation } \\
\text { to locate through current positioning } \\
\text { system }\end{array}$ & $\begin{array}{l}\text { Add increase navigation function by GPS } \\
\text { positioning function and assist App }\end{array}$ \\
\hline $\mathbf{P 2}$ & No place to lay belongings & No design for this function & $\begin{array}{l}\text { Add storage space, ensure the safety of } \\
\text { property, and reminders after the service }\end{array}$ \\
\hline P3 & Environment is too noisy & Mainly distributed in crowed places & $\begin{array}{l}\text { Create an "immersive" relaxed massage } \\
\text { atmosphere }\end{array}$ \\
\hline P4 & $\begin{array}{l}\text { Massage intensity adjustment } \\
\text { requirements }\end{array}$ & $\begin{array}{l}\text { No massage adjustment during } \\
\text { massage }\end{array}$ & $\begin{array}{l}\text { Add the strength adjustment function } \\
\text { mode, including "strong", "medium" and } \\
\text { "soft" grades, and choose massage } \\
\text { techniques, including kneading, } \\
\text { hammering, massage, and foot vibration } \\
\text { function. }\end{array}$ \\
\hline P5 & Temperature adjustment needs & Feel cold during massage & Increase far-infrared heating function \\
\hline P6 & Emergency stop massage needs & $\begin{array}{l}\text { Massage without emergency stop } \\
\text { button }\end{array}$ & $\begin{array}{l}\text { Add emergency stop massage button next } \\
\text { to hands to meet the need for quick pause }\end{array}$ \\
\hline P7 & Delayed massage needs & $\begin{array}{l}\text { Unable to continue massage when } \\
\text { time is up }\end{array}$ & $\begin{array}{l}\text { Simplify re-payment process and extend } \\
\text { massage time at any time }\end{array}$ \\
\hline 01 & Scan code & $\begin{array}{l}\text { After scanning the massage chair, the } \\
\text { massage chair is started immediately } \\
\text { without prompting, causes }\end{array}$ & Remind users to scan code \\
\hline
\end{tabular}




\begin{tabular}{|c|c|c|c|}
\hline & & uncomfortable experience & \\
\hline $\mathbf{O 2}$ & Limited selection mode & Only 3 types of service mode & Provide more types of service mode \\
\hline $\mathbf{O 3}$ & No start massage reminder & $\begin{array}{l}\text { Instant massage after successful } \\
\text { payment }\end{array}$ & Tips and reminder before massage \\
\hline O4 & $\begin{array}{l}\text { Check the continuing massage } \\
\text { time }\end{array}$ & $\begin{array}{l}\text { Display the continuing massage time } \\
\text { by mobile phone App }\end{array}$ & $\begin{array}{l}\text { Increase continuing remaining massage } \\
\text { time function }\end{array}$ \\
\hline O5 & $\begin{array}{l}\text { No preparation at the end of } \\
\text { service }\end{array}$ & $\begin{array}{l}\text { No feedback after massage chair ends } \\
\text { massage }\end{array}$ & $\begin{array}{l}\text { End the massage through music or } \\
\text { atmosphere }\end{array}$ \\
\hline
\end{tabular}

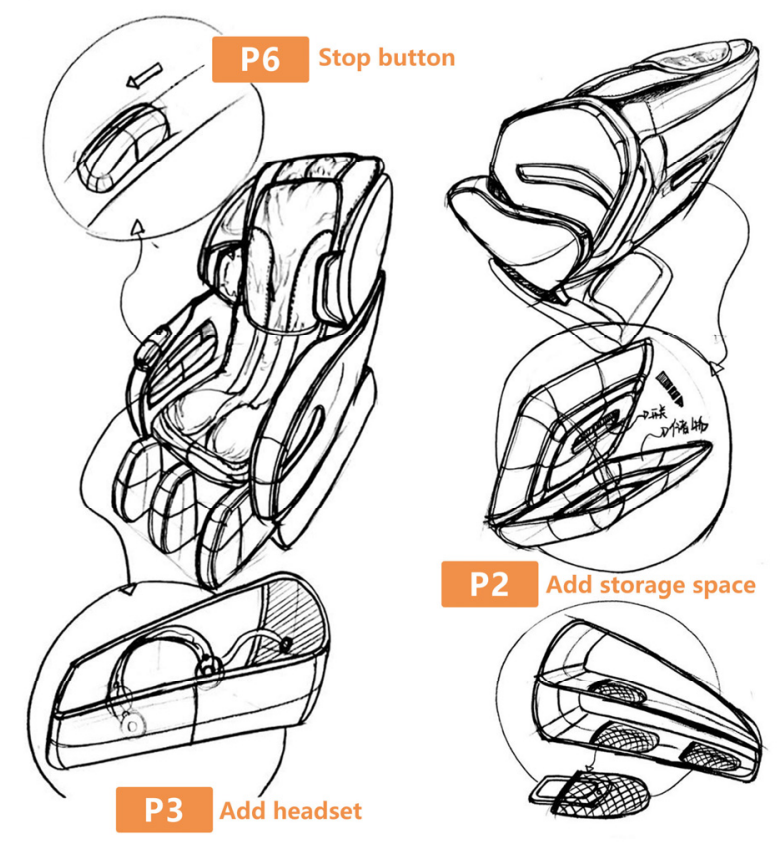

Before

After
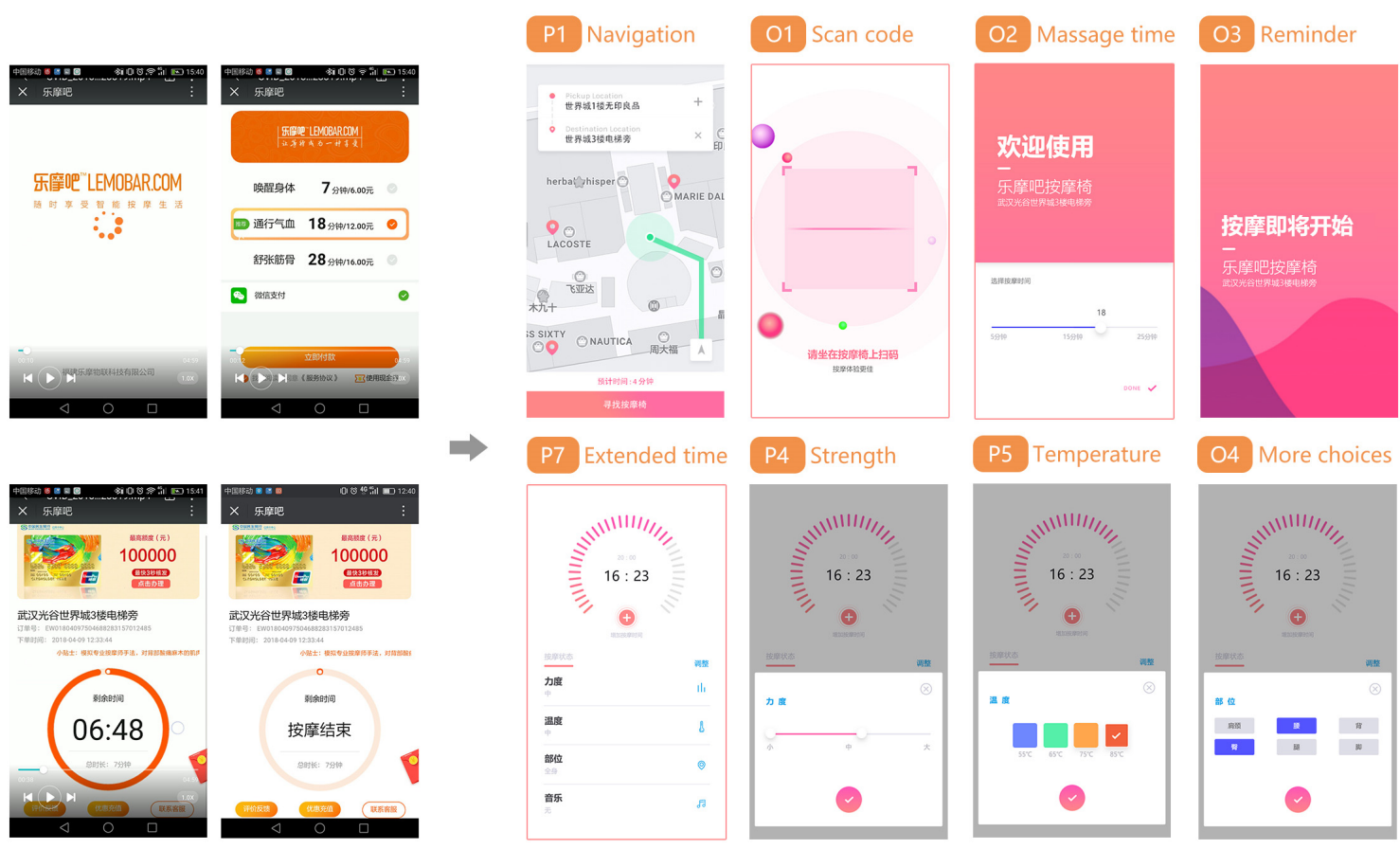

Figure 4. Improved design concepts.

\section{Conclusion}

The user journey map is a reflection of the emotions generated by the user's use of the product's behaviour. This paper aims to analyse the users' $\mathrm{P}$ and $\mathrm{O}$ points through user research and user journey maps, and further tap into potential opportunities for users in shared massage chairs and improve the current sharing of massage chairs. The current status of the product provides users with personalized service. The plan for 
the improvement of the later period will need to be further improved.

\section{Acknowledgment}

Supported by National Natural Science Foundation of China (Grant No: 51708236 )

Supported by Fundamental Research Funds for the Central Universities (Grant No: 2016YXMS273 )

\section{References}

1. Jiang Han. Where are the profitability points of the sharing economy?[J]. Money, 2017(8):10-11.

2. Lei Xuan. Shared Massage Chair: The new consumer style before the opening of the film [J]. China Quality Travel, 2017(8):78-80.

3. Xin Xiangyang. Interaction Design: From Physical Logic to Behavioral Logic [J]. Decoration, 2015(1):58-62.

4. Wang Yumei, Hu Weifeng, Tang Jin, et al. Travel postcard service design based on user experience journey[J]. Packaging Engineering, 2016(22):158163.

5. Lei Xuan. Shared Massage Chair: The new consumer style before the opening of the film [J]. China Quality Travel, 2017(8):78-80.

6. Wu Yanjun. Internet-based Shared Massage System[J]. Internet of Things Technology, 2017, 7(11):74-76. 